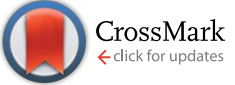

Cite this: RSC Adv., 2017, 7, 3233

\title{
Highly active $\mathrm{MnO}_{x}-\mathrm{CeO}_{2}$ catalyst for diesel soot combustion $\dagger$
}

\begin{abstract}
Han Zhao, ${ }^{\text {ab }}$ Xiaoxia Zhou, ${ }^{a}$ Min Wang, ${ }^{\text {ab }}$ Zhiguo Xie, ${ }^{a}$ Hangrong Chen ${ }^{* a c}$ and Jianlin Shic

A series of $\mathrm{MnO}_{x}-\mathrm{CeO}_{2}$ composites have been prepared via a facile coprecipitation method and used as catalysts for diesel soot combustion. It is found that the content of manganese oxide has a considerable influence on both the morphology and catalytic activity for diesel soot combustion in the copresence of $\mathrm{NO}_{x}$ and $\mathrm{O}_{2}$. Superior catalytic activity $\left(T_{\mathrm{f}}=360{ }^{\circ} \mathrm{C}\right)$ was obtained over the optimized catalyst $\mathrm{CM}_{20}[\mathrm{Mn} /$ $(\mathrm{Mn}+\mathrm{Ce})$ equals to 20 at\%], which is believed to be attributable to the following two aspects: (1) the abundant pore structure, presenting between the loosely-packed homogeneous particles with similar sizes to that of the soot particles, which is beneficial for mass transfer and heat diffusion as well as the sufficient contact between catalyst and soot; (2) high concentration of $\mathrm{Mn}^{4+}$ and $\mathrm{Ce}^{3+}$ cations derived from the charge transfer between $\mathrm{Mn}$ and $\mathrm{Ce}$ species as active sites can adsorb and activate $\mathrm{NO}$ and $\mathrm{O}_{2}$, and then greatly facilitate $\mathrm{NO}_{2}$ production.
\end{abstract}

Received 24th October 2016 Accepted 1st December 2016

DOI: 10.1039/c6ra25738k

www.rsc.org/advances been developed to decrease the soot combustion temperature. Additionally, many researches demonstrate that the introduction of macropores or large voids into the catalysts can greatly facilitate the heat and mass transfer as well as improve the contact between soot and the catalysts, eventually to reach a high activity towards soot oxidation..$^{11,20-25}$ For example, Wei et $a .^{23}$ synthesized a three-dimensionally ordered macroporous (3DOM) $\mathrm{LaFeO}_{3}$ catalyst loaded with tiny golden nanoparticles $(\sim 2.9 \mathrm{~nm})$, showing the temperature of maximum soot combustion rate $\left(T_{\mathrm{m}}\right)$ at $366{ }^{\circ} \mathrm{C}$ under loose contact mode between soot and catalyst. Recently, Nascimento et $a .^{25}$ synthesized $\mathrm{Ag} / \mathrm{CeO}_{x} / \mathrm{FeO}_{y}$ catalysts supported on cordierite for the control of diesel soot emission, showing further decreased $T_{\mathrm{m}}\left(334^{\circ} \mathrm{C}\right.$ ), and $T_{\mathrm{f}}$ (finishing soot combustion temperature, 400 ${ }^{\circ} \mathrm{C}$ ), exhibiting great potential in application. However, the high-cost, the sensitivity to sulfur, and easily sintering characteristic of noble metal catalysts, ${ }^{26,27}$ as well as the difficulty in the synthesis of 3DOM materials hinder the industrial application of this kind of catalysts.

$\mathrm{MnO}_{x}-\mathrm{CeO}_{2}$ composites have been widely used in many catalytic reaction processes, such as wet oxidation of toxic organic pollutants ${ }^{28}$ and oxidation of gaseous ${ }^{29}$ or even liquid pollutants, ${ }^{30}$ and proved to be a promising substitute for noble metal catalysts. But for catalytic soot combustion, the previously reported approaches are still hard to achieve a satisfactory performance on $\mathrm{MnO}_{x}-\mathrm{CeO}_{2}$ composites, i.e., $T_{\mathrm{m}}=393-420{ }^{\circ} \mathrm{C}$, $T_{\mathrm{f}}>400{ }^{\circ} \mathrm{C}$, maybe due to the unsufficient catalyst-soot contact that will restrict the full use of the active sites of the catalysts. ${ }^{10,31-34}$

Herein, a series of $\mathrm{MnO}_{x}-\mathrm{CeO}_{2}$ composites was synthesized through a facile modified coprecipitation method. Especially, 
the optimized catalyst $\mathrm{CM}_{20}[\mathrm{Mn} /(\mathrm{Mn}+\mathrm{Ce})=20$ at $\%]$ shows uniform particle morphology with hierarchically porous structure which is much beneficial to the sufficient contact between catalyst and soot, as well as the high concentration of $\mathrm{Mn}^{4+}$ $\mathrm{Ce}^{3+}$ cations on the surface that favors $\mathrm{NO}_{2}$ production, thus exhibiting an excellent catalytic activity for the removal of soot in $\mathrm{NO}_{x} / \mathrm{O}_{2}$ atmosphere, i.e., ignition temperature $\left(T_{\mathrm{i}}\right)=280{ }^{\circ} \mathrm{C}$, $T_{\mathrm{m}}=326^{\circ} \mathrm{C}$ and $T_{\mathrm{f}}=360^{\circ} \mathrm{C}$. The possible catalytic mechanism for the soot combustion is also proposed.

\section{Experimental}

\subsection{Catalyst preparation}

All the chemicals used in this study were of analytical grade, and were used without further purification. $\mathrm{MnO}_{x}-\mathrm{CeO}_{2}$ composites were prepared by the co-precipitation method reported before ${ }^{35}$ with some modification. A typical preparation procedure is as follows: firstly, $7.5 \mathrm{mmol}$ nitrate including $\mathrm{Ce}\left(\mathrm{NO}_{3}\right)_{3} \cdot 3 \mathrm{H}_{2} \mathrm{O}$ and $\mathrm{Mn}\left(\mathrm{NO}_{3}\right)_{2}$ (50 wt\% in aqueous solution) was dissolved in $30 \mathrm{~mL}$ deionized water. Then, $30 \mathrm{~mL}$ water solution including $30 \mathrm{mmol}$ $\mathrm{NaHCO}_{3}$ was quickly poured into the nitrate solution and the mixture was stirred for $30 \mathrm{~min}$ at room temperature. Next, the precipitates were filtered and washed with deionized water and ethyl alcohol alternately for several times. After drying at $100^{\circ} \mathrm{C}$, the precursors were grinded and then calcined under static air at $500{ }^{\circ} \mathrm{C}$ for $2 \mathrm{~h}$ with a heating rate of $1^{\circ} \mathrm{C} \mathrm{min}^{-1}$. The obtained catalysts were designated $\mathrm{CM}_{y}$, where $y(\%)$ is the $\mathrm{Mn} /(\mathrm{Mn}+\mathrm{Ce})$ atomic ratio in the recipe. In addition, we prepared two single oxides $\left(\mathrm{CeO}_{2}\right.$ and $\left.\mathrm{MnO}_{x}\right)$ for reference with the same synthesis condition.

\subsection{Catalyst characterization}

The nitrogen adsorption and desorption curves were obtained using Micromeritics Tristar 3000 at $77 \mathrm{~K}$, and the specific surface area and the pore size distribution were calculated using the Brunauer-Emmett-Teller (BET) and Barrett-Joyner-Halenda (BJH) methods, respectively. Powder X-ray diffraction (XRD) patterns of the prepared samples were got using a Rigaku D/Max $2200 \mathrm{PC}$ diffractometer with $\mathrm{Cu} \mathrm{K} \alpha$ radiation (40 kV and $40 \mathrm{~mA}$ ). Field emission scanning electron microscopy (FE-SEM) imaging was performed using Hitachi S-4800. Transmission electron microscopic (TEM) images, selected area electron diffraction (SAED) patterns and element mapping images were obtained using a JEOL-2010F electron microscope operated at $200 \mathrm{kV}$. X-ray photoelectron spectroscopy (XPS) signals were recorded using an ESCAlab 250 instrument. The fitting of the Mn element was carried out using Gaussian fitting parameters. The temperatureprogramed reduction with hydrogen $\left(\mathrm{H}_{2}-\mathrm{TPR}\right)$ experiments were performed using a Micromeritics Chemisorb 2750 instrument in a $5 \% \mathrm{H}_{2} / \mathrm{N}_{2}$ flow $\left(25 \mathrm{~mL} \mathrm{~min}{ }^{-1}\right)$ using $50 \mathrm{mg}$ catalyst with a heating rate of $10^{\circ} \mathrm{C} \mathrm{min}^{-1}$. The uptake amount of $\mathrm{H}_{2}$ was measured using a thermal conductivity detector (TCD).

\subsection{Activity testing}

Carbon black from Degussa (diameters: $10-50 \mathrm{~nm}$ ) was used as the model soot particles. Following a well-accepted procedure, soot $(10 \mathrm{mg})$ and catalyst $(100 \mathrm{mg})$ were carefully mixed for 20 min with a spatula to simulate the loose contact mode, then silica pellets $(1 \mathrm{~g})$ were added and mixed by the spatula for another $10 \mathrm{~min}$. It is worth noting that silica pellets were added to avoid pressure drop and favor heat transfer. ${ }^{36} \mathrm{~A}$ gas mixture of $500 \mathrm{ppm} \mathrm{NO}, 10 \% \mathrm{O}_{2}$ and balance $\mathrm{N}_{2}$ was feed with a flow rate of $200 \mathrm{~mL} \mathrm{~min}{ }^{-1}$. The space velocity was thus calculated to be $120000 \mathrm{~mL}\left(\mathrm{~g} \mathrm{~h}^{-1}\right.$. Afterwards, the mixture was heated to $650{ }^{\circ} \mathrm{C}$ at a heating rate of $5{ }^{\circ} \mathrm{C} \mathrm{min}^{-1}$ in a tube furnace equipped with a thermal couple. To minish the error of the measurement to a least extent, the temperature of the tube furnace was monitored with a standard thermal couple, every gas flow was verified with a mechanical flow meter and the concentration of $\mathrm{NO}_{x}$ was measured by a $\mathrm{NO}_{x}$ analyzer (Thermo Fisher 42i-LS). The analysis of the emissions from the reactor was performed using an online GC-FID analyzer (GC2060 from Shanghai Ruimin Instrument Corp. Ltd.) equipped with a methane converter. The catalytic activities (conversion and selectivity) were calculated as indicated in previous reports in the literature, in terms of $T_{\mathrm{i}}, T_{\mathrm{m}}$ and $T_{\mathrm{f}}$ values, which were respectively defined as the temperatures at $10 \%, 50 \%$ and $90 \%$ of soot conversion, and selectivity to $\mathrm{CO}_{2}$ as well, which was quantified: selectivity $(\%)=S_{\mathrm{CO}_{2}}($ total $) /\left[S_{\mathrm{Co}}(\right.$ total $)+S_{\mathrm{CO}_{2}}($ total $\left.)\right]$, where $S_{\mathrm{CO}_{x}}$ (total) represents the area under the $\mathrm{CO}_{x}$-temperature curve in the range of $\mathrm{RT}-650{ }^{\circ} \mathrm{C}(x=1$ or 2$) \cdot{ }^{37,38}$

\section{Results and discussion}

\subsection{Catalytic activity measurements}

Fig. 1 shows the catalytic activity of the $\mathrm{CM}_{y}$ composites, references $\mathrm{MnO}_{x}$ and $\mathrm{CeO}_{2}$, and NULL (without catalyst) towards soot oxidation under loose contact mode. It is obvious that compared with NULL, all the $\mathrm{CM}_{y}$ composites and the references $\mathrm{MnO}_{x}, \mathrm{CeO}_{2}$ show much lower characteristic temperatures and higher selectivity to $\mathrm{CO}_{2}$ in the soot oxidation. Thereinto, $\mathrm{CM}_{20}$ shows the lowest characteristic temperatures $\left(T_{\mathrm{i}}=280^{\circ} \mathrm{C}, T_{\mathrm{m}}=326^{\circ} \mathrm{C}\right.$, and $\left.T_{\mathrm{f}}=360^{\circ} \mathrm{C}\right)$ as well as the highest selectivity to $\mathrm{CO}_{2}(95.6 \%)$, indicating that the interaction between $\mathrm{Mn}$ and Ce species can greatly improve the catalytic activity toward the soot oxidation. Even compared with the noble-metal based catalysts supported on 3DOM oxides or

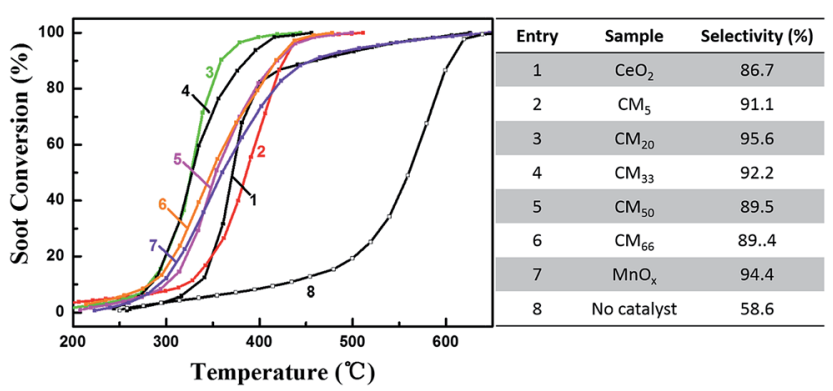

Fig. 1 Catalytic activity (left) and selectivity to $\mathrm{CO}_{2}$ (right) for soot combustion over different catalysts or NULL (without catalyst) under loose contact mode. Reaction conditions: 500 ppm NO and $10 \% \mathrm{O}_{2}$ in

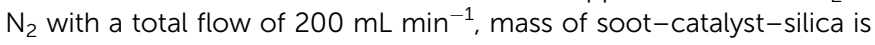
10-100-1000 mg. 
cordierite, as well as the $\mathrm{MnO}_{x}-\mathrm{CeO}_{2}$ catalysts prepared by other methods, $\mathrm{CM}_{20}$ still shows much lower characteristic temperatures (especially $T_{\mathrm{f}}$ ) for soot combustion under similar reaction conditions (loose contact mode, shown in Table S1†). It should be noted that even at a higher space velocity $\left[330000 \mathrm{~mL}\left(\mathrm{~g}_{\text {catal }}\right.\right.$ $\mathrm{h})^{-1}$, the highest one among those shown in Table S1†], $\mathrm{CM}_{20}$ still shows a much lower $T_{\mathrm{m}}$ value $\left(350^{\circ} \mathrm{C}\right)$ than that of other reported $\mathrm{MnO}_{x}-\mathrm{CeO}_{2}$ catalysts $\left(393-420^{\circ} \mathrm{C}\right)$ shown in Table $\mathrm{S} 1 . \dagger$ Fig. $\mathrm{S} 1$ and $\mathrm{S} 2 \uparrow$ indicates good stability in both catalytic activity and structure for these $\mathrm{CM}_{y}$ composite catalysts (herein, $\mathrm{CM}_{33}$ was chosen as an example). In order to understand the different catalytic performances on these prepared catalysts, XRD analysis, $\mathrm{N}_{2}$ adsorption/desorption analysis and SEM/TEM observations were conducted to reveal both the phase composition and the morphology/pore structure of different catalysts.

\subsection{XRD analyses}

Fig. 2 shows the XRD patterns of different $\mathrm{CM}_{y}$ composites and the references $\mathrm{MnO}_{x}$ and $\mathrm{CeO}_{2}$. It is found that the reference $\mathrm{CeO}_{2}$ exhibits a single phase of cubic $\mathrm{CeO}_{2}$ (JCPDS 43-1002), while $\mathrm{MnO}_{x}$ shows three distinguishable manganese oxides of $\mathrm{Mn}_{2} \mathrm{O}_{3}$ (JCPDS 73-1826), $\mathrm{MnO}_{2}$ (JCPDS 72-1982) and $\mathrm{Mn}_{5} \mathrm{O}_{8}$ (JCPDS 39-1218). In addition, compared with reference $\mathrm{CeO}_{2}$, all the $\mathrm{CM}_{y}$ composites show relatively wide diffraction peaks corresponding to cubic $\mathrm{CeO}_{2}$ phase, without detectable Mncontaining phases or obvious peak shift, indicating that manganese oxides may exist in the form of highly dispersive and/or amorphous species, thus decreasing the crystallinity of $\mathrm{CeO}_{2}$. More interestingly, $\mathrm{CM}_{20}$ shows the biggest FWHM (the full width at half maximum) values of the main XRD peaks among all the $\mathrm{CM}_{y}$ composites, suggestive of the smallest crystalline grain according to the Scherrer equation, and the corresponding most abundant surface defect sites, which are beneficial for the improvement of catalytic activity.

\subsection{SEM \& TEM measurements for $\mathrm{CM}_{20}$}

The typical SEM images and the corresponding EDS spectrum, as well as TEM image and the corresponding element mapping

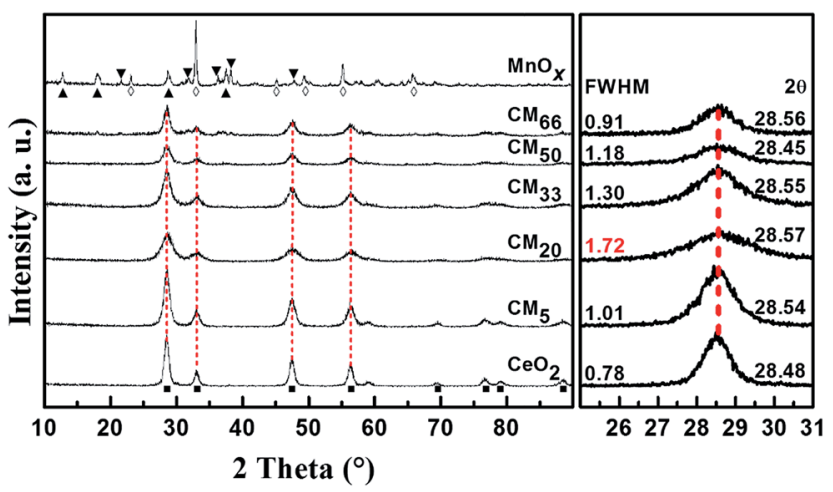

Fig. 2 XRD patterns of different $\mathrm{CM}_{y}$ composites and the references $\mathrm{MnO}_{x}$ and $\mathrm{CeO}_{2}$ (left), ( $-\mathrm{CeO}_{2} ; \diamond-\mathrm{Mn}_{2} \mathrm{O}_{3} ; \boldsymbol{\Delta}-\mathrm{MnO}_{2} ; \boldsymbol{\nabla}-\mathrm{Mn}_{5} \mathrm{O}_{8}$ ), and the enlarged region between $25^{\circ}$ and $31^{\circ}$ of the patterns showing the corresponding FWHM values and peak positions of $2 \theta$ (right). of $\mathrm{CM}_{20}$ shown in Fig. 3 indicate that $\mathrm{CM}_{20}$ is solely composed of uniform particles with loose packing, leaving abundant large pores, as indicated by the arrows in Fig. $3 \mathrm{~b}$, which is very different from the morphologies of all the other studied catalysts in Fig. $\mathrm{S} 3 \dagger\left(\mathrm{CeO}_{2}, \mathrm{CM}_{5}, \mathrm{CM}_{50}, \mathrm{CM}_{66}\right.$ and $\left.\mathrm{MnO}_{x}\right)$. The pore sizes in $\mathrm{CM}_{20}$ are measured to be within 16-103 nm (Fig. $3 \mathrm{~b}$ ), which are consistent with its pore size distribution (10-159 nm) by $\mathrm{N}_{2}$ adsorption/desorption analysis shown in Fig. $\mathrm{S} 4 \uparrow$ and summarized in Table S2. $\dagger$ As can be seen in Table S2, $\dagger$ the specific surface areas of $\mathrm{CM}_{y}$ composites are all larger than that of reference $\mathrm{MnO}_{x}$ and $\mathrm{CeO}_{2}$. Especially, $\mathrm{CM}_{20}$ shows much enlarged specific surface area and pore volume as well. Besides, its pore size is also broadened. It is believed that the similar particle size of the sample $\mathrm{CM}_{20}$ to that of soot particles (Fig. S3$f_{\dagger} \dagger$ ), and the abundant large pores in $\mathrm{CM}_{20}$ are both helpful to its sufficient contact with soot. Also, its high specific surface area and pore volume both favor the dispersion of active sites, thus making a great contribution to catalytic oxidation of soot. The atomic ratio of $\mathrm{Mn} /(\mathrm{Mn}+\mathrm{Ce})$ is calculated to be $21.9 \%$, according to EDS spectrum in Fig. 3c, similar to that of the starting solution. As can be found in Fig. $3 \mathrm{~d}-\mathrm{f}$, both the Ce species and Mn species are homogeneously distributed in the prepared composite, indicating that manganese species shows highly dispersive with ceria species. The $\mathrm{H}_{2}$-TPR results (Fig. S5 $\dagger$ ) confirm the interaction between $\mathrm{Mn}$ and Ce species in $\mathrm{CM}_{y}$ composites. Especially, $\mathrm{CM}_{20}$ shows excellent redox activity, which can be mainly attributed to the interaction between Ce and Mn species, inducing the changes of the local atomic environment for each element, as detected by the following XPS measurements.

\subsection{XPS measurements}

Fig. 4 shows the Mn 2p, Ce $3 \mathrm{~d}$ and O 1s XPS spectra of the series of $\mathrm{CM}_{y}$ composites, as well as the references $\mathrm{MnO}_{x}$ and $\mathrm{CeO}_{2}$. The analysis results of different samples are summarized in Table 1, based on the careful peak fitting procedure. The $\mathrm{O} 1 \mathrm{~s}$ XPS spectra of the sample $\mathrm{CM}_{y}$ and the references $\mathrm{MnO}_{x}$ and $\mathrm{CeO}_{2}$ can be deconvoluted into two components after Gaussian fitting, as shown in Fig. 4c, which can be ascribed to lattice oxygen $\mathrm{O}_{\text {latt }}(529.6 \mathrm{eV})$ and adsorbed oxygen $\mathrm{O}_{\text {ads }}(532.4 \mathrm{eV})$, respectively. Generally, adsorbed oxygen species always correspond to the numbers of oxygen vacancies ${ }^{39}$ which are beneficial for the activation of gaseous oxygen molecules in the feed gas. The existence of oxygen vacancies in $\mathrm{CM}_{y}$ can also be evidently confirmed by the results of Raman spectroscopy analysis (Fig. S6 $\dagger$ ). Compared with reference $\mathrm{CeO}_{2}$, the main peak in the Raman spectra of $\mathrm{CM}_{y}$, the $\mathrm{F}_{2 \mathrm{~g}}$ mode of $\mathrm{CeO}_{2}$ shows a distinct red-shift from 464 to (433-452) $\mathrm{cm}^{-1}$, indicating that the interaction between $\mathrm{Mn}$ and Ce disturbed the fluorite-like structure to some extent and resulted in the formation of the oxygen vacancies in the $\mathrm{CeO}_{2}$ lattice. ${ }^{40} \mathrm{It}$ is noting that the peak at $652 \mathrm{~cm}^{-1}$ for $\mathrm{MnO}_{x}$ also shifts down to (605-637) $\mathrm{cm}^{-1}$ for $\mathrm{CM}_{y}$ composites, which could also be related to the formation of oxygen vacancies in $\mathrm{CM}_{y} .{ }^{40}$ Usually, the high ratio of $\mathrm{O}_{\text {ads }} / \mathrm{O}_{\text {latt }}$ indicates a high activity toward oxidation reaction. But in the present work, $\mathrm{CM}_{20}$, though with the lowest $\mathrm{O}_{\text {ads }} / \mathrm{O}_{\text {latt }}$ ratio 

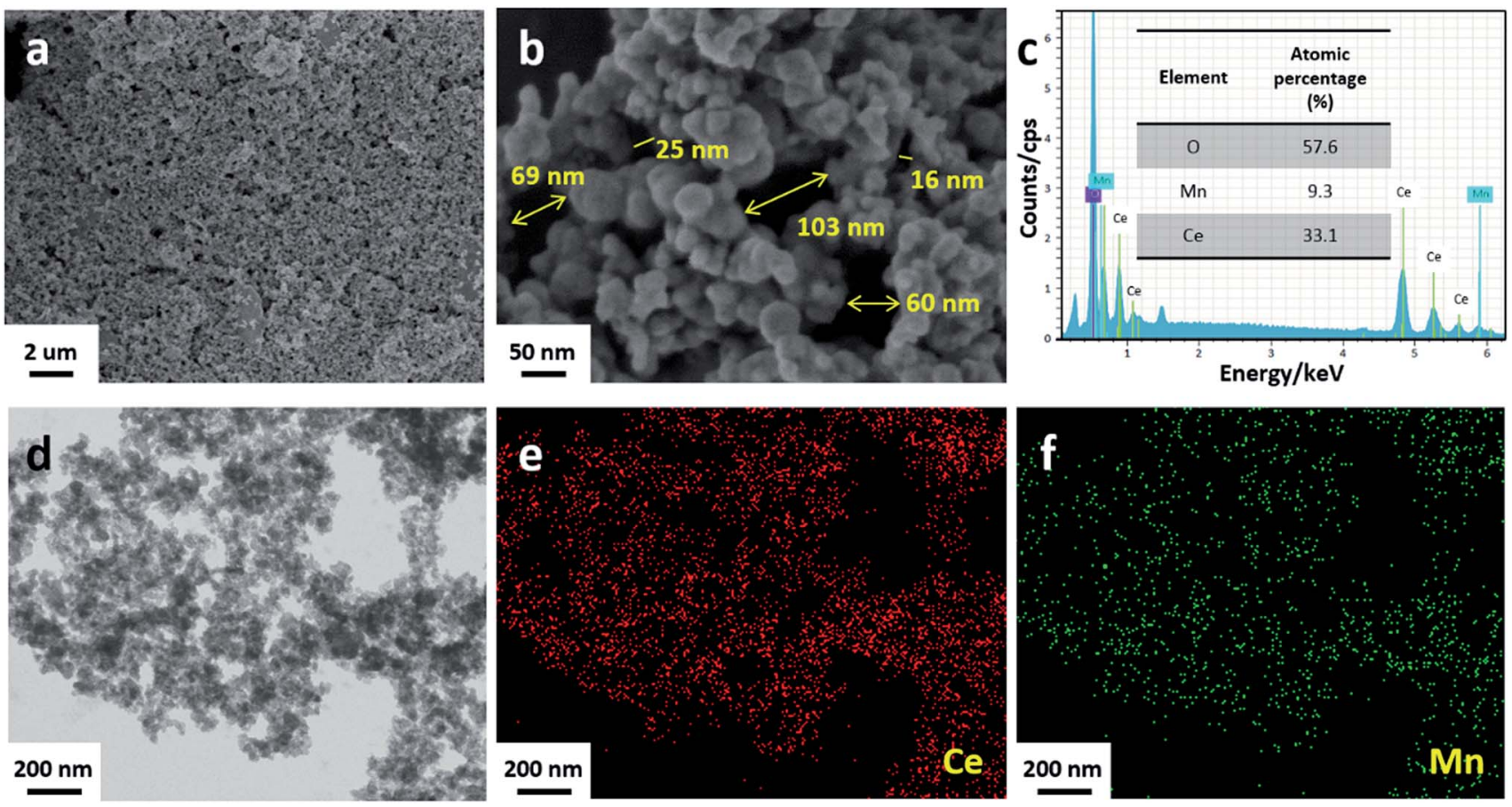

Fig. 3 Low-magnification SEM image (a), high-magnification SEM image (b), EDS spectrum (c), typical TEM image (d) and the element mapping (e and f) of $\mathrm{CM}_{20}$

(a)

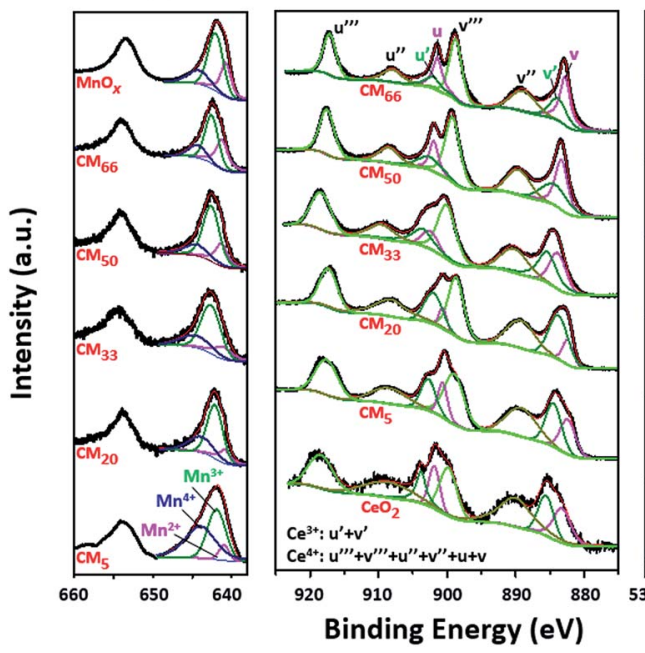

Fig. 4 XPS spectra of (a) Mn 2p, (b) Ce 3d and (c) O 1s for all $\mathrm{CM}_{y}$ composites and the reference $\mathrm{MnO}_{x}$ and/or $\mathrm{CeO}_{2}$.

among all the studied catalysts, still shows the highest catalytic activity for soot combustion in $\mathrm{NO}_{x} / \mathrm{O}_{2}$, which suggests that there exists another key factor besides adsorbed oxygen species determining the catalytic activity.

As shown in the Fig. 4 and Table 1, both Mn and Ce species present various valence states. Thereinto, it is found that the ratio of $\mathrm{Ce}^{3+} /\left(\mathrm{Ce}^{3+}+\mathrm{Ce}^{4+}\right)$ firstly increases and then decreases with the increase of $y$ in $\mathrm{CM}_{y}$, and the value reaches to a maximum value of $27.6 \%$ in $\mathrm{CM}_{20}$, which indicates the charge
Table 1 XPS surface composition analysis of $\mathrm{CM}_{y}$ composites and the references $\mathrm{MnO}_{x}$ and/or $\mathrm{CeO}_{2}$

\begin{tabular}{llll}
\hline Sample & $\begin{array}{l}\mathrm{O}_{\text {ads }} /\left(\mathrm{O}_{\text {ads }}+\mathrm{O}_{\text {latt }}\right) \\
(\%)\end{array}$ & $\begin{array}{l}\mathrm{Mn}^{2+} / \mathrm{Mn}^{3+} / \mathrm{Mn}^{4+} \\
(\%)\end{array}$ & $\begin{array}{l}\mathrm{Ce}^{3+} /\left(\mathrm{Ce}^{3+}+\mathrm{Ce}^{4+}\right) \\
(\%)\end{array}$ \\
\hline $\mathrm{MnO}_{x}$ & 54.9 & $27.5 / 52.1 / 20.3$ & \\
$\mathrm{CM}_{66}$ & 33.3 & $35.2 / 48.7 / 16.1$ & 17.3 \\
$\mathrm{CM}_{50}$ & 31.1 & $22.1 / 56.9 / 21.1$ & 19.2 \\
$\mathrm{CM}_{33}$ & 30.5 & $20.1 / 58.5 / 21.3$ & 24.9 \\
$\mathrm{CM}_{20}$ & 21.2 & $16.0 / 54.9 / 29.0$ & 27.6 \\
$\mathrm{CM}_{5}$ & 27.7 & $8.0 / 56.8 / 35.1$ & 22.0 \\
$\mathrm{CeO}_{2}$ & 46.6 & & 18.2
\end{tabular}

transfer between Mn and Ce within the interface (eqn (1)), as supported by the previous reports demonstrating negative charge transfer either from $\mathrm{Mn}$ to Ce or from Ce to Mn. ${ }^{41-45}$ Such a charge transfer will lead to the strong interaction between Ce and $\mathrm{Mn}$ species and thus the formation of uniform nanoparticles. ${ }^{46}$ This strong interaction between $\mathrm{Mn}$ and Ce can also be reflected in the results of $\mathrm{H}_{2}$-TPR profiles shown in Fig. $\mathrm{S} 5, \dagger$ in which, all of the $\mathrm{CM}_{y}$ composites especially $\mathrm{CM}_{20}$ and $\mathrm{CM}_{33}$ show much lower reduction peak temperature than that for either $\mathrm{MnO}_{x}$ or $\mathrm{CeO}_{2}$. Additionally, it is reported that the $\mathrm{Mn}^{4+}$ and $\mathrm{Ce}^{3+}$ can absorb and activate $\mathrm{NO}$ and $\mathrm{O}_{2},{ }^{47,48}$ thus the $\mathrm{Mn}^{4+}$ and $\mathrm{Ce}^{3+}$ cations could serve as active sites for the catalytic soot combustion in $\mathrm{NO}_{x} / \mathrm{O}_{2}$ atmosphere, by promoting the formation of $\mathrm{NO}_{2}$.

$$
\mathrm{Ce}^{4+}+\mathrm{Mn}^{3+} \leftrightarrow \mathrm{Ce}^{3+}+\mathrm{Mn}^{4+}
$$


To further verify the role of $\mathrm{Mn}^{4+}$ and $\mathrm{Ce}^{3+}$ cations in the catalytic soot oxidation, a parameter " $\Omega$ " (defined in eqn (2)) was introduced to quantify the concentration of $\mathrm{Mn}^{4+}$ and $\mathrm{Ce}^{3+}$ cations in the $\mathrm{CM}_{y}$ composites.

$$
\Omega=a \times b
$$

Where $a=(1-y)\left[\mathrm{Ce}^{3+} /\left(\mathrm{Ce}^{3+}+\mathrm{Ce}^{4+}\right)\right], b=y\left[\mathrm{Mn}^{4+} /\left(\mathrm{Mn}^{2+}+\mathrm{Mn}^{3+}+\right.\right.$ $\left.\mathrm{Mn}^{4+}\right)$ ], and $y$ is that in $\mathrm{CM}_{y}$. Moreover, the relationship between " $\Omega$ " value and the catalytic activity over the different catalysts $\mathrm{CM}_{y}$ are shown in Fig. 5. It is found that for the $\mathrm{CM}_{y}$ composites, the larger $\Omega$ value is, the higher catalytic activity is, which confirms the role of $\mathrm{Mn}^{4+}$ and $\mathrm{Ce}^{3+}$ cations as active sites for catalytic soot combustion in $\mathrm{NO}_{x} / \mathrm{O}_{2}$ over $\mathrm{CM}_{y}$ composites. Nevertheless, the sample $\mathrm{CM}_{66}$ seems an exception with a lower $\Omega$ value, showing higher catalytic activity than $\mathrm{CM}_{50}$, which can be ascribed to the higher specific surface area and pore volume of $\mathrm{CM}_{66}\left(72 \mathrm{~m}^{2} \mathrm{~g}^{-1}\right.$ and $0.22 \mathrm{~cm}^{3} \mathrm{~g}^{-1}$, Table $\left.\mathrm{S} 2 \dagger\right)$ than those of $\mathrm{CM}_{50}\left(53 \mathrm{~m}^{2} \mathrm{~g}^{-1}\right.$ and $0.11 \mathrm{~cm}^{3} \mathrm{~g}^{-1}$, Table $\left.\mathrm{S} 2 \dagger\right)$.

\subsection{SEM and TEM measurements for $\mathrm{CM}_{33}$}

It is worth noting that, compared with $\mathrm{CM}_{20}, \mathrm{CM}_{33}$ shows a little lower catalytic activity and $\Omega$ value, and similar specific surface area but significantly lower pore volume. Therefore, the TEM and SEM analyses for $\mathrm{CM}_{33}$ were further performed, as shown in Fig. 6. It can be found that very different from the homogeneous morphology of $\mathrm{CM}_{20}$ particles shown in Fig. $3, \mathrm{CM}_{33}$ shows some complex morphology in addition to the highly dispersive particles, such as micro-flakes (1 in Fig. $6 \mathrm{c}$ ) and microspheres (3 in Fig. 6c). These two kinds of morphologies can also be found in the Ce-rich samples $\left(\mathrm{CeO}_{2}\right.$ and $\mathrm{CM}_{5}$ in Fig. S3†), and the Mnrich samples $\left(\mathrm{CM}_{50}, \mathrm{CM}_{66}\right.$ and $\mathrm{MnO}_{x}$ in Fig. $\left.\mathrm{S} 3 \dagger\right)$, respectively. Apparently, either the micro-flakes or the microsphere morphology in $\mathrm{CM}_{33}$ lacks the porous structure, thus leading to the lower pore volume than $\mathrm{CM}_{20}$ (Table $\mathbf{S} 2 \dagger$ ), which can strongly affect the efficient contact between catalyst and soot

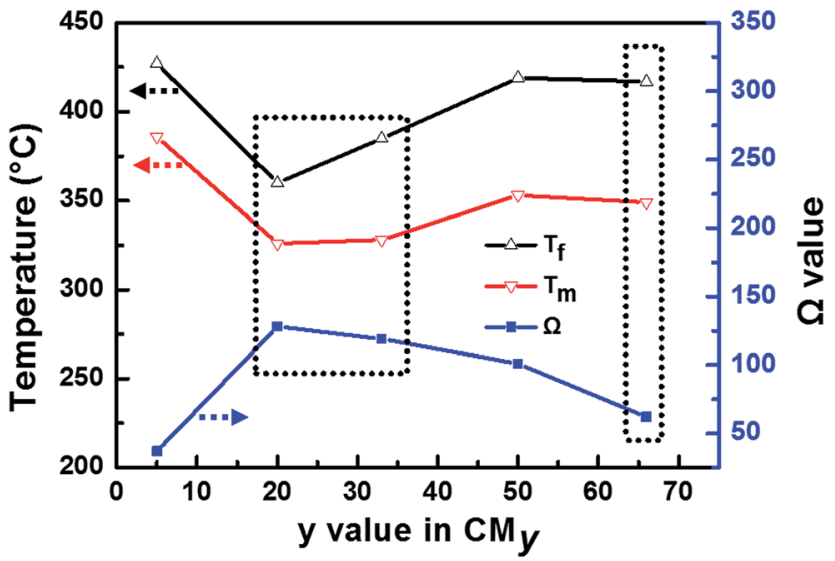

Fig. 5 The different characteristic temperatures $\left(T_{m}\right.$ and $\left.T_{f}\right)$ and values of " $\Omega$ " as a function of $y$ in $\mathrm{CM}_{y}$. Reaction conditions for catalytic soot combustion: 500 ppm NO and $10 \% \mathrm{O}_{2}$ in $\mathrm{N}_{2}$ with a total flow of 200

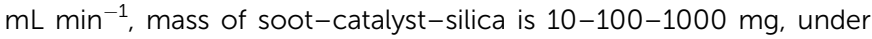
loose contact mode.

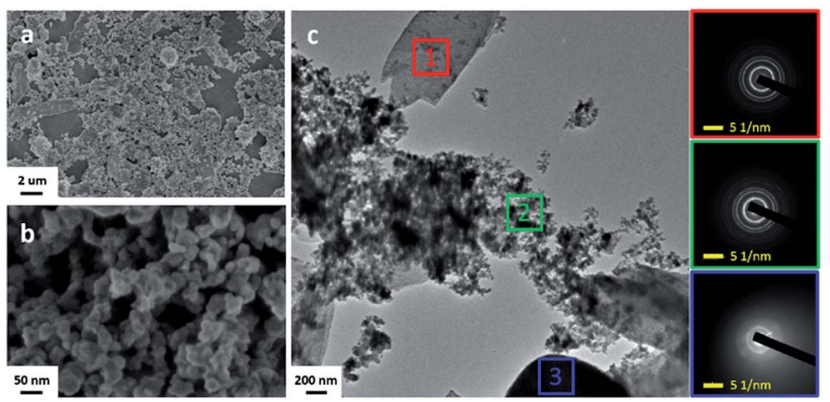

Fig. 6 Low-magnification SEM image (a), high-magnification SEM image (b), TEM image (c) of $\mathrm{CM}_{33}$, and the corresponding SAED patterns to the different areas in (c).

particles and decrease the activity for soot oxidation. Nevertheless, the main component in $\mathrm{CM}_{33}$ still presents similar size and chemical composition (Fig. 6b, 2 in Fig. $6 \mathrm{c}$ and S7†) to $\mathrm{CM}_{20}$ particles (Fig. 3), thus it remains higher catalytic activity than other reference samples. Therefore, it is reconfirmed that the homogeneous particles morphology with hierarchically porous structure is one of the key factors in the catalytic process of soot oxidation.

Overall, the catalytic activity for soot oxidation in $\mathrm{NO}_{x} / \mathrm{O}_{2}$ atmosphere can be ascribed to the following two aspects: (1) abundant $\mathrm{Mn}^{4+}$ and $\mathrm{Ce}^{3+}$ cations (large $\Omega$ value) serve as active sites by promoting $\mathrm{NO}_{2}$ production, e.g., $\mathrm{CM}_{20}$ with the largest $\Omega$ value $(\Omega=128)$ shows the best activity toward the soot oxidation. (2) The high surface area and pore volume as well as the typical morphology of the particles with hierarchically porous structure could improve the dispersion of active species and soot diffusion, e.g., $\mathrm{CM}_{66}$ with a lower $\Omega$ value $(\Omega=62)$ exhibits a relatively high activity for soot oxidation due to its high specific surface area and pore volume.

\subsection{A possible catalytic mechanism for soot oxidation}

Based on the above results and analyses, a possible mechanism for the catalytic soot combustion in $\mathrm{NO}_{x} / \mathrm{O}_{2}$ over the sample $\mathrm{CM}_{20}$ was proposed, as shown in Scheme 1. In this catalytic reaction, the efficient contact between the catalyst and soot, and the abundant active $\mathrm{Mn}^{4+}-\mathrm{Ce}^{3+}$ species are two crucial issues determining the excellent catalytic performance. Generally, soot combustion over catalyst in $\mathrm{NO}_{x} / \mathrm{O}_{2}$ atmospheres is believed to follow two different pathways: ${ }^{49}$ (i) direct soot combustion by surface active oxygen species, (ii) NO-aided soot combustion. In Route (i), oxygen species absorbed and activated by oxygen vacancies $\left(\mathrm{V}_{\mathrm{O}}\right)$ on the catalyst surface can directly oxidize soot into $\mathrm{CO}_{2}$ (reaction (3), where $\mathrm{O}^{*}$ is the active oxygen species). ${ }^{50}$

$$
\mathrm{O}^{*}+\mathrm{C} \rightarrow \mathrm{CO}_{2}+\mathrm{V}_{\mathrm{O}}
$$

While in Route (ii), the NO-aided soot combustion can be expressed as the following reactions:

$$
\mathrm{NO}_{\mathrm{ads}}+\mathrm{Mn}^{4+} \rightarrow \mathrm{NO}^{+}-\mathrm{Mn}^{3+}
$$




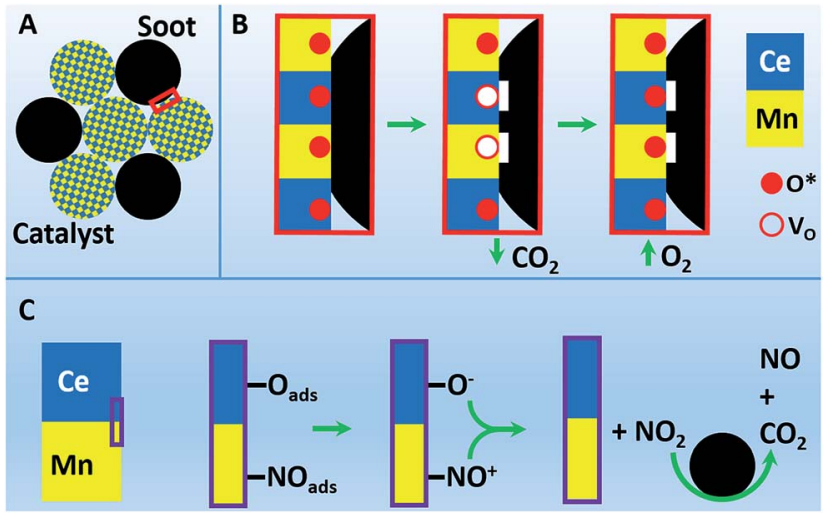

Scheme 1 Schematic illustration of (A) the sufficient mixing of $\mathrm{CM}_{20}$ and soot particles, and the possible pathways of soot combustion on $\mathrm{CM}_{20}$ in $\mathrm{NO}_{x} / \mathrm{O}_{2}$ : (B) Route (i): direct soot combustion by surface active oxygen species; (C) Route (ii): NO-aided soot combustion.

$$
\begin{gathered}
\mathrm{O}_{\mathrm{ads}}+\mathrm{Ce}^{3+} \rightarrow \mathrm{O}^{-}-\mathrm{Ce}^{4+} \\
\mathrm{NO}^{+}-\mathrm{Mn}^{3+}+\mathrm{O}^{-}-\mathrm{Ce}^{4+} \rightarrow \mathrm{NO}_{2}+\mathrm{Mn}^{3+}+\mathrm{Ce}^{4+} \\
\mathrm{NO}_{2}+\mathrm{C} \rightarrow \mathrm{CO}_{2}+\mathrm{NO}
\end{gathered}
$$

As supported by previous reports, it can be rationally deduced that the abundant $\mathrm{Mn}^{4+}$ and $\mathrm{Ce}^{3+}$ cations in $\mathrm{CM}_{20}$ play different roles in the catalytic process. Therein, $\mathrm{Mn}^{4+}$ could adsorb and activate NO into active species $\mathrm{NO}^{+}$, as shown in reaction (4); ${ }^{47}$ while $\mathrm{Ce}^{3+}$ could activate the absorbed oxygen $\mathrm{O}_{\text {ads }}$ into $\mathrm{O}^{-}$(reaction $\left.(5)\right) .^{48}$ Such resultant $\mathrm{NO}^{+}$and $\mathrm{O}^{-}$species will react with each other to form $\mathrm{NO}_{2}$ at the interface between Ce and Mn oxides (reaction (6)), ${ }^{51}$ meanwhile, the produced $\mathrm{Ce}^{4+}-\mathrm{Mn}^{3+}$ will react through reaction (1) to recover the active site $\mathrm{Ce}^{3+}-\mathrm{Mn}^{4+}$, thus completing the catalysis cycle. Then in

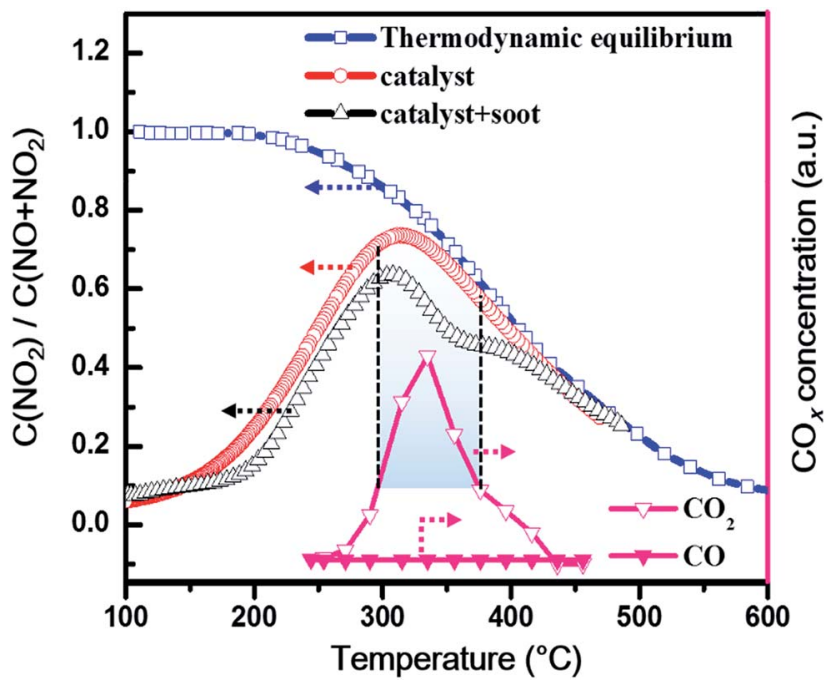

Fig. 7 The temperature-programed oxidation of $\mathrm{NO}$ over $\mathrm{CM}_{33}$ with or without soot under loose contact mode. Reaction conditions: $500 \mathrm{ppm} \mathrm{NO}$ and $10 \% \mathrm{O}_{2}$ in $\mathrm{N}_{2}$ with a total flow of $200 \mathrm{~mL} \mathrm{~min}^{-1}$, the mass of (soot-)catalyst-silica is (10-)100-1000 mg. reaction (7), ${ }^{52}$ the produced $\mathrm{NO}_{2}$, as a stronger oxidant than $\mathrm{O}_{2}$, can be reduced back to NO by soot, which meanwhile can be oxidized to $\mathrm{CO}_{2}$ at low temperatures. In order to further confirm the role of $\mathrm{NO}_{x}$ in the catalytic soot oxidation process, the temperature-programed oxidation of $\mathrm{NO}$ over $\mathrm{CM}_{33}$ with or without soot was further investigated, as shown in Fig. 7. It was found that with the addition of soot into the catalytic NO oxidation system, the $\mathrm{NO}_{2}$ proportion in $\mathrm{NO}_{x}\left(=\mathrm{NO}+\mathrm{NO}_{2}\right)$ decreases in temperature range $200-400{ }^{\circ} \mathrm{C}$, especially in the range of $300-375{ }^{\circ} \mathrm{C}$, where the $\mathrm{CO}_{2}$ concentration reaches its peak values. This coincidence confirms the reaction between $\mathrm{NO}_{2}$ and $\mathrm{C}$, which facilitates $\mathrm{CO}_{2}$ production at the expense of $\mathrm{NO}_{2}$ (reaction (7)). Moreover, catalysis activity measurement over $\mathrm{CM}_{20}$ without the presence of $\mathrm{NO}$ was also conducted for comparison to the case with NO existing in the feed gas, as shown in Fig. S8, $\dagger$ clearly demonstrating the positive effect of NO on the catalytic activity towards soot oxidation.

\section{Conclusions}

In summary, a facile co-precipitation method has been adopted to prepare a series of $\mathrm{MnO}_{x}-\mathrm{CeO}_{2}$ composites for the catalytic oxidation of soot in the simulated diesel emission. Thereinto, the optimized $\mathrm{CM}_{20}$ shows the highest catalytic activity $\left(T_{\mathrm{f}}=360\right.$ ${ }^{\circ} \mathrm{C}$ ), under loose contact mode. The excellent catalytic activity can be attributed to its uniform particle morphology with hierarchically porous structure and the rich active $\mathrm{Mn}^{4+}$ and $\mathrm{Ce}^{3+}$ cations resulting from the suitable doping amount of $\mathrm{Mn}$, which greatly accelerate soot oxidation in $\mathrm{NO}_{x} / \mathrm{O}_{2}$. A possible mechanism was proposed to interpret the role of $\mathrm{Mn}^{4+}-\mathrm{Ce}^{3+}$ species as well as the active oxygen species in the catalytic process of soot combustion in $\mathrm{NO}_{x} / \mathrm{O}_{2}$. The $\mathrm{MnO}_{x}-\mathrm{CeO}_{2}$ composites prepared by this low-cost and easily-scalable method could find the promising practical application in the catalytic removal of soot in the diesel exhaust.

\section{Acknowledgements}

This research was sponsored by National Key Basic Research Program of China (2013CB933200), China National Funds for Distinguished Young Scientists (51225202) and National Natural Science Foundation of China (51502330).

\section{Notes and references}

1 H. Horvath, Atmos. Environ., 1993, 27, 293-317.

2 L. L. N. Guarieiro, A. F. de Souza, E. A. Torres and J. B. de Andrade, Atmos. Environ., 2009, 43, 2754-2761.

3 Z. Gao and W. Schreiber, Proc. Inst. Mech. Eng., Part D, 2002, 216, 619-628.

4 D. B. Kittelson, J. Aerosol Sci., 1998, 29, 575-588.

5 D. Fino, Sci. Technol. Adv. Mater., 2007, 8, 93-100.

6 B. A. A. L. van Setten, M. Makkee and J. A. Moulijn, Catal. Rev.: Sci. Eng., 2001, 43, 489-564.

7 E. Obeid, L. Lizarraga, M. N. Tsampas, A. Cordier, A. Boréave, M. C. Steil, G. Blanchard, K. Pajot and P. Vernoux, J. Catal., 2014, 309, 87-96. 
8 X. H. Yu, Z. Zhao, Y. C. Wei, J. Liu, J. M. Li, A. J. Duan and G. Y. Jiang, Chin. J. Catal., 2015, 36, 1957-1967.

9 J. O. Uchisawa, A. Obuchi, Z. Zhao and S. Kushiyama, Appl. Catal., B, 1998, 18, L183-L187.

10 X. D. Wu, S. Liu, F. Lin and D. Weng, J. Hazard. Mater., 2010, 181, 722-728.

11 J. F. Xu, J. Liu, Z. Zhao, C. M. Xu, J. X. Zheng, A. J. Duan and G. Y. Jiang, J. Catal., 2011, 282, 1-12.

12 D. Fino, N. Russo, G. Saracco and V. Specchia, J. Catal., 2006, 242, 38-47.

13 L. Castoldi, R. Matarrese, L. Lietti and P. Forzatti, Appl. Catal., B, 2009, 90, 278-285.

14 J. Liu, Z. Zhao, J. Q. Wang, C. M. Xu, A. J. Duan, G. Y. Jiang and Q. Yang, Appl. Catal., B, 2008, 84, 185-195.

15 P. Sudarsanam, B. Hillary, B. Mallesham, B. G. Rao, M. H. Amin, A. Nafady, A. M. Alsalme, B. M. Reddy and S. K. Bhargava, Langmuir, 2016, 32, 2208-2215.

16 S. Putla, M. H. Amin, B. M. Reddy, A. Nafady, K. A. Al Farhan and S. K. Bhargava, ACS Appl. Mater. Interfaces, 2015, 7, 16525-16535.

17 P. Sudarsanam, K. Kuntaiaha and B. M. Reddy, New J. Chem., 2014, 38, 5991-6001.

18 P. Sudarsanam, B. Hillary, D. K. Deepa, M. H. Amin, B. Mallesham, B. M. Reddy and S. K. Bhargava, Catal. Sci. Technol., 2015, 5, 3496-3500.

19 P. Sudarsanam, A. Rangaswamy and B. M. Reddy, RSC Adv., 2014, 4, 46378-46382.

20 G. B. Zhang, H. R. Chen, Y. Gong, Z. Shu, D. N. He, Y. Zhu, X. X. Zhou, X. Q. Fan, H. J. Zhang and J. L. Shi, Catal. Commun., 2013, 35, 105-109.

21 E. D. Banus, V. G. Milt, E. E. Miro and M. A. Ulla, Appl. Catal., $B, 2013,132,479-486$.

22 K. Krishna, A. Bueno-Lopez, M. Makkee and J. A. Moulijn, Appl. Catal., B, 2007, 75, 189-200.

23 Y. C. Wei, J. Liu, Z. Zhao, Y. Chen, C. Xu, A. Duan, G. Jiang and H. He, Angew. Chem., Int. Ed., 2011, 50, 2326-2329.

24 C. M. Cao, Y. X. Zhang, D. S. Liu and M. Meng, Small, 2015, 11, 3659-3664.

25 L. F. Nascimento, J. F. Lima, P. C. de Sousa Filho and O. A. Serra, Chem. Eng. J., 2016, 290, 454-464.

26 Y. Nagahara, S. Sugawara and K. Shinohara, J. Power Sources, 2008, 182, 422-428.

27 I. Heo, J. W. Choung, P. S. Kim, I. S. Nam, Y. I. Song, C. B. In and G. K. Yeo, Appl. Catal., B, 2009, 92, 114-125.

28 S. T. Hussain, A. Sayari and F. C. Larachi, Appl. Catal., B, 2001, 34, 1-9.

29 D. Delimaris and T. Ioannides, Appl. Catal., B, 2008, 84, 303312.
30 X. Y. Wang, Q. Kang and D. Li, Appl. Catal., B, 2009, 86, 166175.

31 X. D. Wu, F. Lin, L. Wang, D. Weng and Z. Zhou, J. Environ. Sci., 2011, 23, 1205-1210.

32 M. L. Fu, K. L. Wang, R. P. Yu, X. E. Wen, M. Zhang, B. C. Huang, J. L. Wu, D. Q. Ye and H. Liang, Chin. J. Inorg. Chem., 2012, 28, 1593-1600.

33 H. L. Zhang, Y. Zhu, S. D. Wang, M. Zhao, M. C. Gong and Y. Q. Chen, Fuel Process. Technol., 2015, 137, 38-47.

34 F. Lin, X. D. Wu, S. Liu, D. Weng and Y. Y. Huang, Chem. Eng. J., 2013, 226, 105-112.

35 L. N. Cai, Z. H. Hu, P. Branton and W. C. Li, Chin. J. Catal., 2014, 35, 159-167.

36 X. D. Wu, F. Lin, H. B. Xu and D. Weng, Appl. Catal., B, 2010, 96, 101-109.

37 J. Liu, Z. Zhao, J. Q. Wang, C. M. Xu, A. J. Duan, G. Y. Jiang and Q. Yang, Appl. Catal., B, 2008, 84, 185-195.

38 A. L. Kustov and M. Makkee, Appl. Catal., B, 2009, 88, 263271.

39 S. H. Xie, Y. X. Liu, J. G. Deng, X. T. Zhao, J. Yang, K. F. Zhang, Z. Han and H. X. Dai, J. Catal., 2016, 342, 17-26.

40 X. M. Zhang, Y. Q. Deng, P. F. Tian, H. H. Shang, J. Xu and Y. F. Han, Appl. Catal., B, 2016, 191, 179-191.

41 Z. Zeng and M. Greenblatt, Phys. Rev. B: Condens. Matter Mater. Phys., 2001, 63, 224410.

42 S. Imamura, Ind. Eng. Chem. Res., 1999, 38, 1743-1753.

43 X. D. Wu, H. N. Yu, D. Weng, S. Liu and J. Fan, J. Rare Earths, 2013, 31, 1141-1147.

44 P. Venkataswamy, D. Jampaiah, F. J. Lin, I. Alxneit and B. M. Reddy, Appl. Surf. Sci., 2015, 349, 299-309.

45 F. Larachi, J. Pierre, A. Adnot and A. Bernis, Appl. Surf. Sci., 2002, 195, 236-250.

46 J. Verhelst, D. Decroupet and D. de Vos, Catal. Sci. Technol., 2013, 3, 1579-1590.

47 J. Wang, J. Z. Zhu, X. X. Zhou, Y. Y. Du, W. M. Huang, J. J. Liu, W. Q. Zhang, J. L. Shi and H. R. Chen, J. Mater. Chem. A, 2015, 3, 7631-7638.

48 D. Jampaiah, K. M. Tur, S. J. Ippolito, Y. M. Sabri, J. Tardio, S. K. Bhargava and B. M. Reddy, RSC Adv., 2013, 3, 1296312974.

49 S. Liu, X. D. Wu, D. Weng and R. Ran, J. Rare Earths, 2015, 33, 567-590.

50 P. G. Harrison, I. K. Ball, W. Daniell, P. Lukinskas, M. Cespedes, E. E. Miro and M. A. Ulla, Chem. Eng. J., 2003, 95, 47-55.

51 Z. P. Wang, M. X. Chen and W. F. Shangguan, Acta Phys.Chim. Sin., 2009, 25, 79-85.

52 S. J. Jelles, R. R. Krul, M. Makee and J. A. Moulijn, Catal. Today, 1999, 53, 623-630. 